\title{
Association of Preoperative Nutritional Status with Prognosis in Patients with Esophageal Cancer Undergoing Salvage Esophagectomy
}

\author{
MAKOTO SAKAI, MAKOTO SOHDA, TATSUYA MIYAZAKI, TOMONORI YOSHIDA, \\ YUJI KUMAKURA, HIROAKI HONJO, KEIGO HARA, DAIGO OZAWA, \\ SHIGEMASA SUZUKI, NARITAKA TANAKA, TAKEHIKO YOKOBORI and HIROYUKI KUWANO \\ Department of General Surgical Science, Gunma University, Graduate School of Medicine, Maebashi, Japan
}

\begin{abstract}
Background: To investigate whether malnutrition is associated with poor prognosis of patients who undergo salvage esophagectomy. We examined the association between the preoperative prognostic nutritional index (PNI) and prognosis of patients who undergo salvage esophagectomy. Patients and Methods: We conducted a single-center retrospective study and reviewed hospital patient records for tumor characteristics and patient outcomes. Univariate and multivariate survival analyses were carried out using the Cox proportional hazards regression model. Results: Thirty-two patients with esophageal squamous cell carcinoma (ESCC) who underwent salvage esophagectomy between 1998 and 2015 at our Institute were included in this study. Univariate analysis revealed that clinical response $(p=0.045)$, preoperative PNI $(p<0.001), p T$ $(p=0.024), p N(p=0.004)$, and residual tumors $(p<0.001)$ were significant prognostic factor for overall survival. Multivariate analysis using age and these five variables found no independent prognostic factors. Multivariate analysis using three preoperative variables (age, clinical response, and preoperative $P N I$ ) revealed that $P N I$ was an independent prognostic preoperative factor for overall survival ( $p=0.005)$. Conclusion: Preoperative nutritional status is associated with the prognosis of patients undergoing salvage esophagectomy.
\end{abstract}

Salvage esophagectomy is now thought to be the only established therapeutic strategy that provides any chance of long-term survival after local failure for patients with

Correspondence to: Makoto Sakai, Department of General Surgical Science, Gunma University, Graduate School of Medicine, 3-39-22 Showa-machi, Maebashi, Gunma 371-8511, Japan. Tel: +81 27220822, Fax: +81 272208230, e-mail: maksakai@gunma-u.ac.jp

Key Words: Esophageal neoplasms prognosis, nutritional status, salvage esophagectomy. esophageal squamous cell carcinoma (ESCC) receiving definitive chemoradiotherapy (CRT) (1, 2). However, previous studies demonstrated that salvage esophagectomy was associated with high morbidity and mortality rates (1, 3). Long-term outcome of salvage esophagectomy also remains poor, with 5-year survival rate after salvage esophagectomy of $0-33 \%$ as described by Watanabe et al. (4) and references therein. When conducting and performing this type of high-risk operation, the patient's nutritional status must not be ignored. Malnutrition has been reported in 60$85 \%$ of patient with esophageal cancer. Immunosuppression and malnourished state have been suggested to occur in patients following definitive $\operatorname{CRT}(5,6)$. To date, several studies have reported prognostic factors for patients undergoing salvage esophagectomy, such as pretreatment tumor depth and lymph node metastasis, response to initial CRT, pathological tumor depth and lymph node metastasis, and $\mathrm{R} 0$ resection (1, 7-9). However, the actual impact of preoperative nutritional status on the prognosis of patients who undergo salvage esophagectomy remains unclear. Thus, we hypothesized that malnutrition is associated with the poor prognosis of patients who undergo salvage esophagectomy. To investigate this hypothesis, we examined the association between the preoperative prognostic nutritional index (PNI), a simple and efficient parameter for evaluating nutritional condition, and prognosis of patients who undergo salvage esophagectomy by univariate and multivariate analysis.

\section{Patients and Methods}

Patients. This retrospective study was approved by the Ethics Committee of the Graduate School of Medicine, Gunma University (approval number 1457). Written informed consent was obtained from all patients before treatment. The criteria for inclusion were patients with ESCC who underwent salvage esophagectomy between 1998 and 2015 at our Institute. Patients were excluded from this study if they had no data on serum albumin and lymphocyte count in peripheral blood within 1 month before surgery 


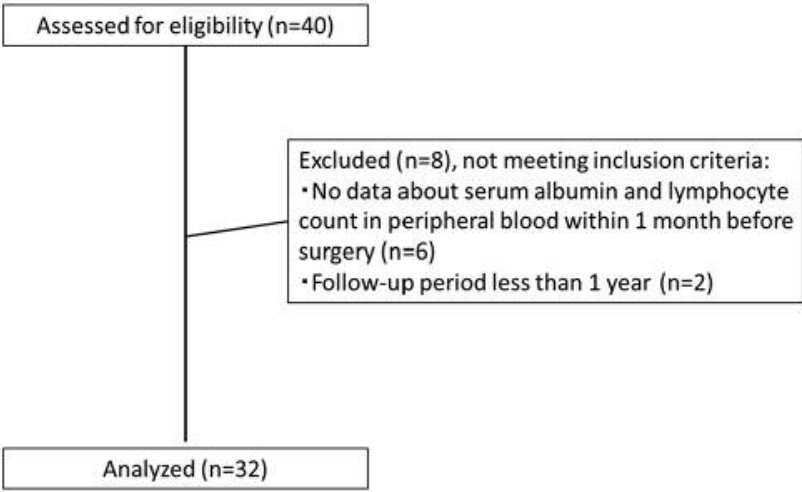

Figure 1. Flow chart showing patient recruitment.
Table I. Patient characteristics.

\begin{tabular}{lc}
\hline Characteristic & Value \\
\hline Age at primary treatment, (years) & \\
Mean (SD) & $69.16(7.96)$ \\
Gender (\%) & $29(90.6)$ \\
Male & $3(9.4)$ \\
Female & \\
Location of tumor $(\%)$ & $7(21.9)$ \\
Cervical & $15(46.9)$ \\
Upper-middle & $10(31.2)$ \\
Lower & \\
cT* $\%)$ & $11(34.4)$ \\
T1-2 & $21(65.6)$ \\
T3-4 & \\
cN*(\%) & $11(34.4)$ \\
Negative & $21(65.6)$ \\
Positive & \\
cM*(\%) & $31(96.9)$ \\
M0 & $1(3.1)$ \\
M1 & \\
Resectability* (\%) & $20(62.5)$ \\
Resectable & $12(37.5)$ \\
Unresectable & \\
Concurrent chemotherapy (\%) & $23(71.9)$ \\
Yes & $9(28.1)$ \\
No & \\
Clinical response (\%) & $20(62.5)$ \\
Incomplete & $12(37.5)$ \\
\hline &
\end{tabular}

SD: Standard deviation.*Diagnosed before initial chemoradiotherapy/ radiotherapy.

\section{Results}

Patient characteristics. The flowchart presented in Figure 1 outlines this study. A total of 40 patients were assessed for eligibility for inclusion in the study. Subsequently, eight patients were excluded. Six patients were excluded for having no data on serum albumin and lymphocyte count in peripheral blood within 1 month before surgery, and two surviving patients for follow-up period less than 1 year. The remaining 32 patients were included in this study. Table I summarizes the baseline characteristics, and Table II summarizes the perioperative data of patients.

Survival analysis. Univariate analysis revealed that clinical response, preoperative PNI, pT, pN, and residual tumors were a significant prognostic factor for overall survival (Table III). Multivariate analysis using age and these five variables found no independent prognostic factors (Table IV). Multivariate analysis using three preoperative variables (age, clinical response, and preoperative PNI) revealed PNI was an independent prognostic preoperative 
Table II. Perioperative data.

\begin{tabular}{|c|c|}
\hline Characteristic & Value \\
\hline \multicolumn{2}{|c|}{ Duration from CRT/RT to surgery (months) } \\
\hline Mean (SD) & $21.11(34.59)$ \\
\hline \multicolumn{2}{|l|}{ Type of esophagectomy (\%) } \\
\hline Transcervical & $4(12.5)$ \\
\hline Transthoracic & $20(62.5)$ \\
\hline Transhiatal & $8(25.0)$ \\
\hline \multicolumn{2}{|l|}{ Operation time (min) } \\
\hline Mean (SD) & $491.23(116.09)$ \\
\hline \multicolumn{2}{|l|}{ Blood loss (g) } \\
\hline Mean (SD) & $923.93(651.98)$ \\
\hline \multicolumn{2}{|l|}{ PNI } \\
\hline Mean (SD) & $43.06(4.76)$ \\
\hline \multicolumn{2}{|l|}{ BMI $\left(\mathrm{kg} / \mathrm{m}^{2}\right)$} \\
\hline Mean (SD) & $20.77(2.73)$ \\
\hline \multicolumn{2}{|l|}{$\mathrm{pT}(\%)$} \\
\hline $\mathrm{T} 1-2$ & $14(43.8)$ \\
\hline T3-4 & $18(56.2)$ \\
\hline \multicolumn{2}{|l|}{$\mathrm{pN}(\%)$} \\
\hline Negative & $24(75.0)$ \\
\hline Positive & $8(25.0)$ \\
\hline \multicolumn{2}{|l|}{ Residual tumors (\%) } \\
\hline R0 & $24(75.0)$ \\
\hline $\mathrm{R} 1 / 2$ & $8(25.0)$ \\
\hline \multicolumn{2}{|l|}{ Preoperative complications (\%) } \\
\hline Absent & $18(56.2)$ \\
\hline Present & $14(43.8)$ \\
\hline \multicolumn{2}{|l|}{ Postoperative complications (\%) } \\
\hline Absent & 15 (46.9) \\
\hline Present & $17(53.1)$ \\
\hline \multicolumn{2}{|l|}{ Status at study end (\%) } \\
\hline Death from primary cancer & $11(34.4)$ \\
\hline Death from other illness & $9(28.1)$ \\
\hline Alive & $12(37.5)$ \\
\hline
\end{tabular}

CRT/RT: Chemoradiotherapy/radiotherapy; BMI: body mass index; PNI: prognostic nutritional index; SD: standard deviation.

factor for overall survival (Table V). We divided patients into two groups based on PNI value according to previous reports (12): low PNI (PNI <45) and high PNI (PNI $\geq 45)$. The overall survival rate was significantly higher in patients with high PNI than in those with low PNI ( $p=0.037$; Figure 2). However, disease-specific survival rate had no significant difference according to PNI value $(p=0.424$; Figure 3$)$.

Comparison of background of esophageal cancer survivors after salvage esophagectomy. Table VI summarizes the baseline characteristics of survivors from primary esophageal cancer, living patients and patients who died from noncancer -related causes. Preoperative PNI of living patients was significantly higher than those of patients dying from non-cancer causes $(p=0.044)$.
Table III. Univariate analysis for overall survival.

\begin{tabular}{|c|c|c|}
\hline Characteristic & HR $(95 \% \mathrm{CI})$ & $p$-Value \\
\hline \multicolumn{3}{|l|}{ Preoperative variables } \\
\hline \multicolumn{3}{|l|}{ Age at primary treatment } \\
\hline Per unit increase & $0.9918(0.9351-1.052)$ & 0.785 \\
\hline \multicolumn{3}{|l|}{$\mathrm{cT}^{*}$} \\
\hline T1-2 (reference) & 1 & 0.290 \\
\hline T3-4 & $1.952(0.566-6.732)$ & \\
\hline \multicolumn{3}{|l|}{$\mathrm{cN}^{*}$} \\
\hline Negative (reference) & 1 & 0.265 \\
\hline Positive & $1.78(0.2891-1.832)$ & \\
\hline \multicolumn{3}{|l|}{ Resectability* } \\
\hline Unresectable (reference) & 1 & 0.500 \\
\hline Resectable & $0.7277(0.6461-4.904)$ & \\
\hline \multicolumn{3}{|l|}{ Concurrent chemotherapy } \\
\hline No (reference) & 1 & 0.640 \\
\hline Yes & $0.7951(0.304-2.08)$ & \\
\hline \multicolumn{3}{|l|}{ Clinical response } \\
\hline Incomplete (reference) & 1 & 0.045 \\
\hline Complete & $0.3943(0.1589-0.9789)$ & \\
\hline \multicolumn{3}{|c|}{ Duration from CRT/RT to surgery } \\
\hline Per unit increase & $0.9908(0.9693-1.013)$ & 0.408 \\
\hline \multicolumn{3}{|l|}{ Preoperative PNI } \\
\hline \multicolumn{3}{|l|}{ Per unit increase } \\
\hline Perioperative variables & $0.8377(0.754-0.9306)$ & $<0.001$ \\
\hline \multicolumn{3}{|l|}{ Operation time } \\
\hline Per unit increase & $0.9991(0.9947-1.004)$ & 0.698 \\
\hline \multicolumn{3}{|l|}{ Blood loss } \\
\hline Per unit increase & $0.9998(0.9991-1.001)$ & 0.680 \\
\hline \multicolumn{3}{|l|}{ Preoperative complications } \\
\hline Absent (reference) & 1 & 0.061 \\
\hline Present & $2.350(09601-5.752)$ & \\
\hline \multicolumn{3}{|l|}{ Postoperative complications } \\
\hline Absent (reference) & 1 & 0.437 \\
\hline Present & $1.428(0.5818-3.505)$ & \\
\hline \multicolumn{3}{|l|}{$\mathrm{pT}$} \\
\hline T1-2 (reference) & 1 & 0.024 \\
\hline T3-4 & $3.1(1.163-8.264)$ & \\
\hline \multicolumn{3}{|l|}{$\mathrm{pN}$} \\
\hline Negative (reference) & 1 & 0.004 \\
\hline Positive & $4.982(1.679-14.78)$ & \\
\hline \multicolumn{3}{|l|}{ Residual tumors } \\
\hline R0 (reference) & 1 & $<0.001$ \\
\hline $\mathrm{R} 1 / 2$ & $5.018(1.982-12.7)$ & \\
\hline
\end{tabular}

CRT/RT: Chemoradiotherapy/radiotherapy; PNI: prognostic nutritional index; HR: hazard ratio, $95 \%$ CI: $95 \%$ confidence interval. *Diagnosed before initial CRT/RT.

\section{Discussion}

The most significant finding of the present study was that PNI was an independent prognostic preoperative factor for overall survival of patients with ESCC undergoing salvage esophagectomy. Additionally, the preoperative PNI of patients who remained alive was significantly higher than 


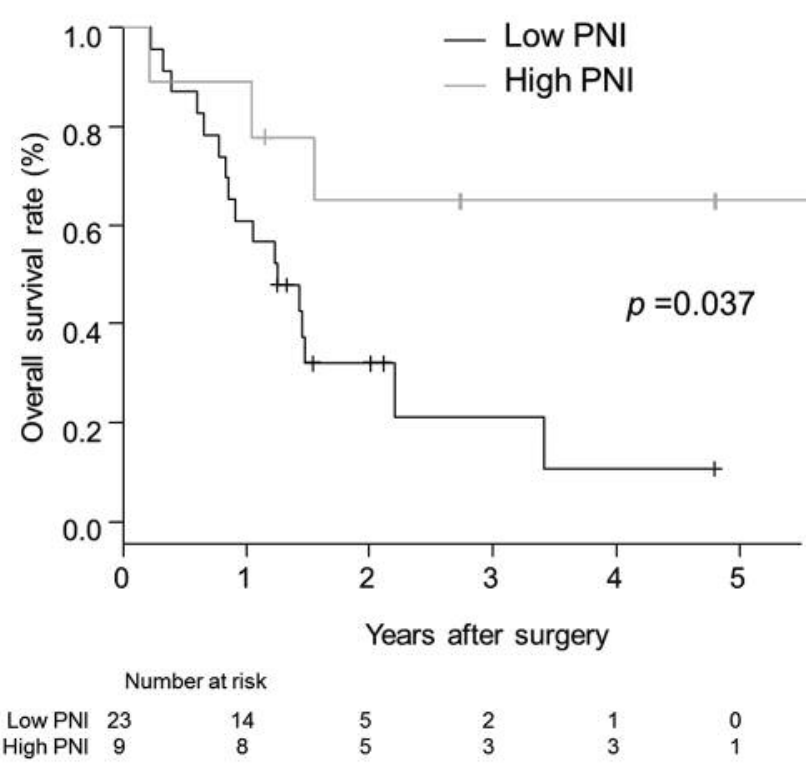

Figure 2. Overall survival of patients who underwent salvage esophagectomy for esophageal squamous cell carcinoma according to their prognostic nutritional index (PNI). The overall survival rate was significantly higher in patients with high PNI than in those with low PNI ( $p=0.037)$.

Table IV. Multivariate analysis for overall survival.

\begin{tabular}{|c|c|c|}
\hline Characteristic & $\operatorname{HR}(95 \% \mathrm{CI})$ & $p$-Value \\
\hline \multicolumn{3}{|l|}{ Age at primary treatment } \\
\hline Per unit increase & $1.01(0.93-1.09)$ & 0.871 \\
\hline \multicolumn{3}{|l|}{ Clinical response } \\
\hline Incomplete (reference) & 1 & \\
\hline Complete & $0.90(0.81-1.00)$ & 0.641 \\
\hline \multicolumn{3}{|l|}{ Preoperative PNI } \\
\hline Per unit increase & $0.90(0.81-1.00)$ & 0.054 \\
\hline \multicolumn{3}{|l|}{$\mathrm{pT}$} \\
\hline T1-2 (reference) & 1 & \\
\hline $\mathrm{T} 3-4$ & $1.38(0.35-5.39)$ & 0.647 \\
\hline \multicolumn{3}{|l|}{$\mathrm{pN}$} \\
\hline Negative (reference) & 1 & \\
\hline Positive & $2.95(0.59-14.61)$ & 0.186 \\
\hline \multicolumn{3}{|l|}{ Residual tumor } \\
\hline R0 (reference) & 1 & \\
\hline $\mathrm{R} 1 / 2$ & $2.02(0.55-7.35)$ & 0.287 \\
\hline
\end{tabular}

PNI: Prognostic nutritional index; HR: hazard ratio, 95\% CI: $95 \%$ confidence interval.

that of patients dying from non-cancer-related causes among survivors from primary cancer. These results support our hypothesis that preoperative nutritional status is associated with the prognosis of patients who undergo salvage esophagectomy.

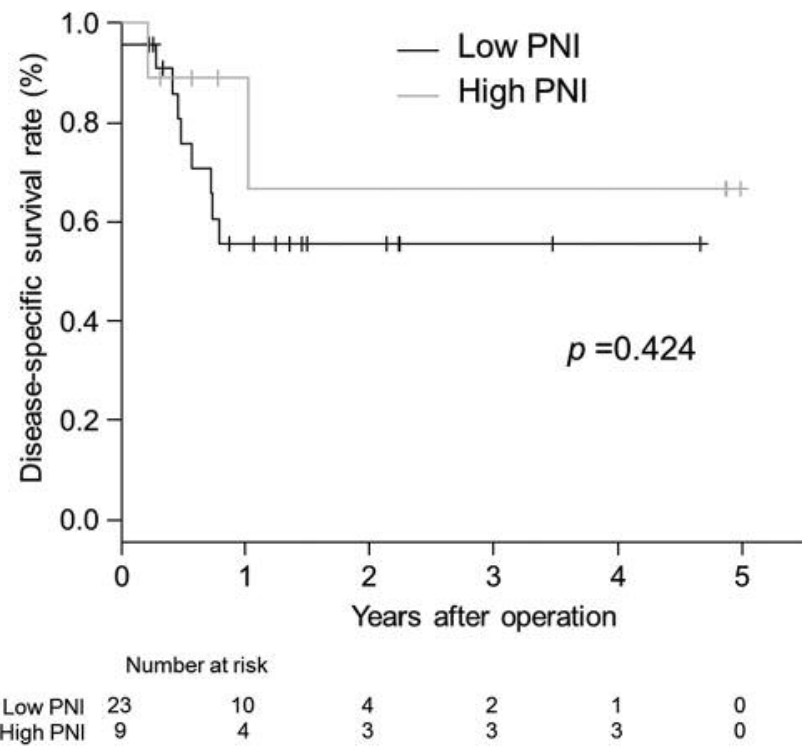

Figure 3. Disease-specific survival of patients who underwent salvage esophagectomy for esophageal squamous cell carcinoma according to their prognostic nutritional index (PNI). The disease-specific survival rate did not significantly differ according to PNI value $(p=0.424)$.

Table V. Multivariate analysis of preoperative variables for overall survival.

\begin{tabular}{lcc}
\hline Characteristic & HR $(95 \% \mathrm{CI})$ & $p$-Value \\
\hline Age at primary treatment & & \\
$\quad$ Per unit increase & $0.98(0.93-1.04)$ & 0.590 \\
$\begin{array}{l}\text { Clinical response } \\
\quad \text { Incomplete (reference) }\end{array}$ & 1 & \\
$\quad$ Complete & $2.01(0.74-5.43)$ & 0.170 \\
Preoperative PNI & $0.86(0.77-0.95)$ & 0.005 \\
$\quad$ Per unit increase & \\
\hline
\end{tabular}

PNI: Prognostic nutritional index; HR: hazard ratio, 95\% CI: 95\% confidence interval.

The PNI is one of the tools and is calculated using the serum albumin level and the total lymphocyte count. PNI was previously proposed as a marker to predict the prognosis of patients with gastrointestinal malignancies (12). Although Nozoe et al. had already reported PNI was correlated with the incidence of postoperative complications and prognosis in patients with ESCC (13), to our best knowledge, this is the first study to report a relationship between PNI and prognosis of patients with ESCC who underwent salvage esophagectomy.

Malnutrition has been reported to be associated with poor outcomes and is characterized by a decreased quality of life, 
Table VI. Characteristics of survivors from primary cancer at study end.

\begin{tabular}{|c|c|c|c|}
\hline Characteristic & Death from non-cancer-related cause & Alive & $p$-Value \\
\hline \multicolumn{4}{|c|}{ Age at primary treatment (years) } \\
\hline Mean (SD) & $74.22(6.50)$ & $70.00(6.49)$ & 0.157 \\
\hline \multicolumn{4}{|c|}{ Concurrent chemotherapy, n (\%) } \\
\hline Yes & $2(22.2)$ & $3(25.0)$ & \multirow[t]{2}{*}{0.999} \\
\hline No & $7(77.8)$ & $9(75.0)$ & \\
\hline \multicolumn{4}{|l|}{ PNI } \\
\hline Mean (SD) & $42.17(3.09)$ & $45.57(3.90)$ & 0.044 \\
\hline \multicolumn{4}{|c|}{ Preoperative complications, $\mathrm{n}(\%)$} \\
\hline Absent & $4(44.4)$ & $9(75.0)$ & \multirow[t]{2}{*}{0.203} \\
\hline Present & $5(55.6)$ & $3(25.0)$ & \\
\hline \multicolumn{4}{|c|}{ Postoperative complications, n (\%) } \\
\hline Absent & $2(22.2)$ & $7(58.3)$ & \multirow[t]{2}{*}{0.184} \\
\hline Present & $7(77.8)$ & $5(41.7)$ & \\
\hline
\end{tabular}

PNI: Prognostic nutritional index; SD: standard deviation.

weaker response to chemotherapy, and lower survival rates in esophageal cancer (14). Focused on salvage esophagectomy, several preoperative factors ( $\mathrm{T}$ and $\mathrm{N}$ status at initial treatment, time to relapse, and complete response to initial treatment) and postoperative factors (tumor pathological stage, $\mathrm{R} 0$ resection and total number of dissected mediastinal lymph nodes) have been reported as prognostic factors as described by Watanabe et al. (4) and references therein. However, the actual impact of preoperative nutritional status on the prognosis of patients underwent salvage esophagectomy was unclear. In our study, clinical response, preoperative PNI, $\mathrm{pT}, \mathrm{pN}$, and residual tumors were a significant prognostic factor for overall survival based on univariate analysis. Although multivariate analysis using age and those five variables found no independent prognostic factors, multivariate analysis using three preoperative variables (age, clinical response, and preoperative PNI) revealed PNI was an independent favorable prognostic preoperative factor for overall survival. Our results showed that preoperative nutritional status had a unignorable effect on the long-term outcome after salvage esophagectomy.

In our study, the overall survival rate was significantly higher in patients with high PNI than in those with low PNI. However, the disease-specific survival rate did not significantly differ according to PNI value. Therefore, we next hypothesized that preoperative nutritional status is also associated with death from other illness of survivors after salvage esophagectomy for esophageal cancer. Comparing baseline characteristics of survivors from primary esophageal cancer, preoperative PNI of patients who were alive was significantly higher than those of patients dying of other causes $(p=0.044)$. In general, cancer survivors have been recognized to have significantly elevated risk of morbidity due to chronic health conditions (15). Nutrition has a major role in the etiology of chronic health conditions, and poor nutritional status may worsen these morbidities in cancer survivors (16). After receiving definitive CRT, patients are considered to be immune-suppressed, and salvage esophagectomy exacerbates immune suppression even in cancer survivors because of its high invasiveness. Thus, the preoperative nutritional status may predict the postoperative healthy condition even of cancer-free patients after salvage esophagectomy. Perioperative immunonutrition was recently reported to improve both the nutritional and immunological status of surgical patients and reduce the risk of postoperative complications (17-18). Regarding the clinical application of our findings, to improve the outcome of salvage esophagectomy, we speculate that patients with ESCC with poor nutritional status may require more intensive perioperative nutritional support, stricter criteria for salvage surgery and long-term chronic health condition management.

Our study has several potential limitations. Firstly, this was a retrospective study and was performed without randomization of patient selection. Secondly, since we assessed nutritional status as PNI, it remains unclear whether analysis using other nutritional indicators, such as the neutrophil-to-lymphocyte ratio and sarcopenia, would lead to the same results.

In conclusion, our study demonstrated that PNI was an independent prognostic preoperative factor for overall survival of patients who underwent salvage esophagectomy for ESCC. Additionally, preoperative PNI of patients remaining alive was significantly higher than that of patients dying from non-cancer-related causes among survivors from primary cancer. Preoperative nutritional status is associated with the poor prognosis of patients who undergo salvage esophagectomy. 


\section{References}

1 Miyata H, Yamasaki M, Takiguchi S, Nakajima K, Fujiwara Y, Nishida T, Mori M and Doki Y: Salvage esophagectomy after definitive chemoradiotherapy for thoracic esophageal cancer. J Surg Oncol 100: 442-446, 2009.

2 Tachimori Y: Role of salvage esophagectomy after definitive chemoradiotherapy. Gen Thorac Cardiovasc Surg 57: 71-78, 2009.

3 D'Journo XB, Michelet P, Dahan L, Doddoli C, Seitz JF, Giudicelli R, Fuentes PA and Thomas PA: Indications and outcome of salvage surgery for oesophageal cancer. Eur J Cardiothorac Surg 33: 1117-1123, 2008.

4 Watanabe M, Mine S, Nishida K, Yamada K, Shigaki H, Matsumoto A and Sano T: Salvage esophagectomy after definitive chemoradiotherapy for patients with esophageal squamous cell carcinoma: Who really benefits from this high-risk surgery? Ann Surg Oncol 22: 4438-4444, 2015.

5 Morita M, Masuda T, Okada S, Yoshinaga K, Saeki H, Tokunaga E, Endo K, Emi Y, Kakeji Y and Maehara Y: Preoperative chemoradiotherapy for esophageal cancer: factors associated with clinical response and postoperative complications. Anticancer Res 29: 2555-2562, 2009.

6 Saeki H, Masuda T, Okada S, Ando K, Sugiyama M, Yoshinaga K, Endo K, Sadanaga N, Emi Y, Kakeji Y, Morita M, Yamashita $\mathrm{N}$ and Maehara $\mathrm{Y}$ : Impact of perioperative peripheral blood values on postoperative complications after esophageal surgery. Surg Today 40: 626-631, 2010.

7 Swisher SG, Wynn P, Putnam JB, Mosheim MB, Correa AM, Komaki RR, Ajani JA, Smythe WR, Vaporciyan AA, Roth JA and Walsh GL: Salvage esophagectomy for recurrent tumors after definitive chemotherapy and radiotherapy. J Thorac Cardiovasc Surg 123: 175-183, 2002.

8 Morita M, Kumashiro R, Hisamatsu Y, Nakanishi R, Egashira A, Saeki H, Oki E, Ohga T, Kakeji Y, Tsujitani S, Yamanaka T and Maehara Y: Clinical significance of salvage esophagectomy for remnant or recurrent cancer following definitive chemoradiotherapy. J Gastroenterol 46: 1284-1291, 2011.

9 Wang S, Tachimori Y, Hokamura N, Igaki H, Nakazato H and Kishino T: Prognostic analysis of salvage esophagectomy after definitive chemoradiotherapy for esophageal squamous cell carcinoma: the importance of lymphadenectomy. J Thorac Cardiovasc Surg 147: 1805-1811, 2014.
10 Sobin L, Gospodarowicz M WC: TNM Classification of Malignant Tumours, Seventh Edition. Wiley: pp. 243-246, 2009.

11 Onodera T, Goseki N and Kosaki G: Prognostic nutritional index in gastrointestinal surgery of malnourished cancer patients. Nihon Geka Gakkai Zasshi 85: 1001-1005, 1984.

12 Zhao Y, Xu P, Kang H, Lin S, Wang M, Yang P, Dai C, Liu X, Liu K, Zheng Y, Dai Z, Zhao Y, Xu P, Kang H, Lin S, Wang M, Yang P, Dai C, Liu X, Liu K, Zheng Y and Dai Z: Prognostic nutritional index as a prognostic biomarker for survival in digestive system carcinomas. Oncotarget 5: 86573-86583, 2016.

13 Nozoe T, Ninomiya M, Maeda T, Matsukuma A, Nakashima H and Ezaki T: Prognostic nutritional index: a tool to predict the biological aggressiveness of gastric carcinoma. Surg Today 40 : 440-443, 2010.

14 Miller KR and Bozeman MC: Nutrition therapy issues in esophageal cancer. Curr Gastroenterol Rep 14: 356-366, 2012.

15 Edwards BK, Noone A-M, Mariotto AB, Simard EP, Boscoe FP, Henley SJ, Jemal A, Cho H, Anderson RN, Kohler BA, Eheman CR and Ward EM: Annual Report to the Nation on the status of cancer, 1975-2010, featuring prevalence of comorbidity and impact on survival among persons with lung, colorectal, breast, or prostate cancer. Cancer 120: 1290-314, 2014.

16 Zhang FF, Liu S, John EM, Must A and Demark-Wahnefried W: Diet quality of cancer survivors and noncancer individuals: Results from a national survey. Cancer 121: 4212-4221, 2015.

17 Takeuchi H, Ikeuchi S, Kawaguchi Y, Kitagawa Y, Isobe Y, Kubochi K, Kitajima M and Matsumoto S: Clinical significance of perioperative immunonutrition for patients with esophageal cancer. World J Surg 31: 2160-2167, 2007.

18 Mudge L, Isenring $\mathrm{E}$ and Jamieson GG: Immunonutrition in patients undergoing esophageal cancer resection. Dis Esophagus 24: 160-165, 2011.
Received October 24, 2017

Revised November 16, 2017

Accepted November 23, 2017 